\title{
Evaluation of Binder Jetting and Chemical Vapor Infiltration as a Production Method for Silicon Carbide Parts for Nuclear Applications
}

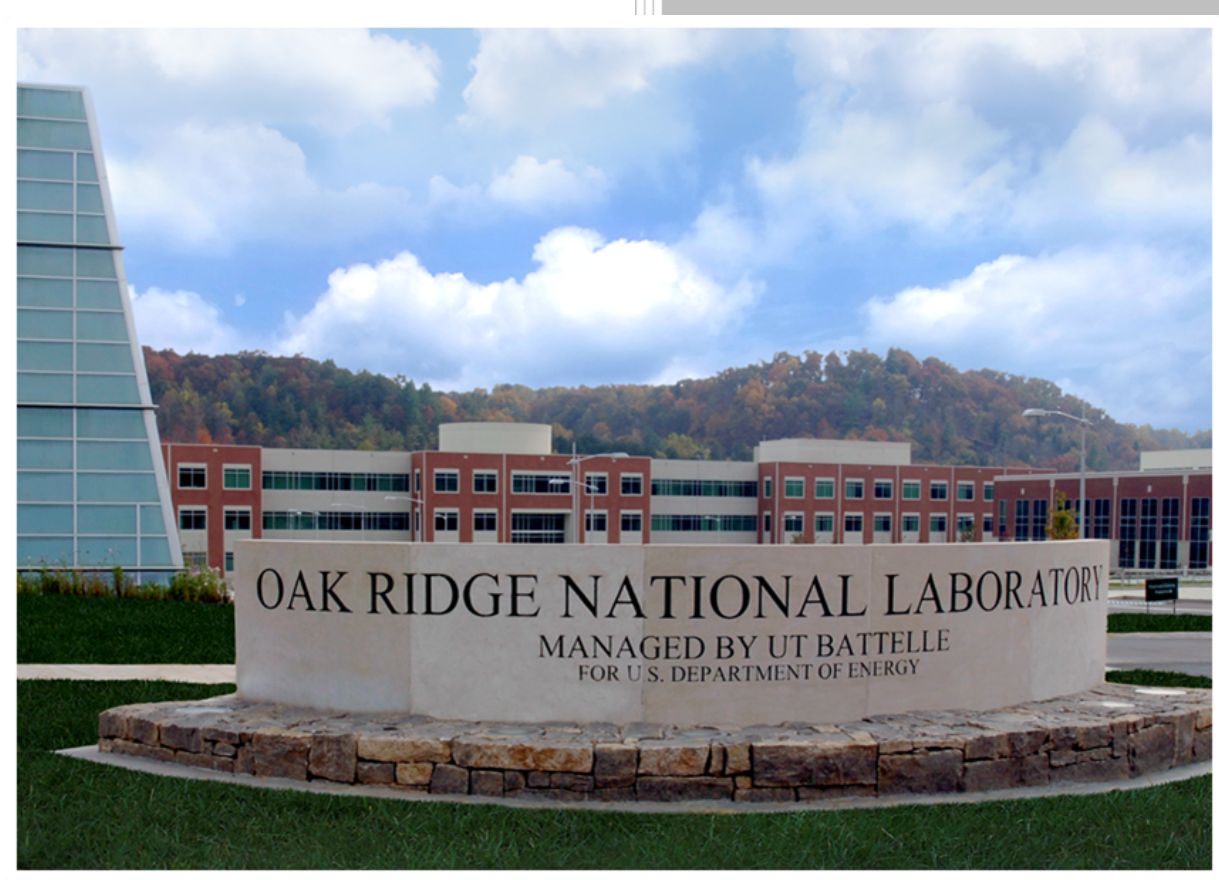

Approved for public release.

Amy Elliott Corson Cramer Kurt Terrani

09/27/2019 Distribution is unlimited. 


\section{DOCUMENT AVAILABILITY}

Reports produced after January 1, 1996, are generally available free via US Department of Energy (DOE) SciTech Connect.

Website www.osti.gov

Reports produced before January 1, 1996, may be purchased by members of the public from the following source:

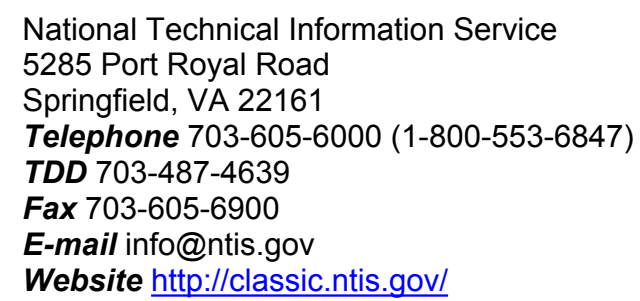

Reports are available to DOE employees, DOE contractors, Energy Technology Data Exchange representatives, and International Nuclear Information System representatives from the following source:

Office of Scientific and Technical Information

PO Box 62

Oak Ridge, TN 37831

Telephone 865-576-8401

Fax 865-576-5728

E-mail reports@osti.gov

Website http://www.osti.gov/contact.html

This report was prepared as an account of work sponsored by an agency of the United States Government. Neither the United States Government nor any agency thereof, nor any of their employees, makes any warranty, express or implied, or assumes any legal liability or responsibility for the accuracy, completeness, or usefulness of any information, apparatus, product, or process disclosed, or represents that its use would not infringe privately owned rights. Reference herein to any specific commercial product, process, or service by trade name, trademark, manufacturer, or otherwise, does not necessarily constitute or imply its endorsement, recommendation, or favoring by the United States Government or any agency thereof. The views and opinions of authors expressed herein do not necessarily state or reflect those of the United States Government or any agency thereof. 


\title{
EVALUATION OF BINDER JETTING AND CHEMICAL VAPOR INFILTRATION AS A PRODUCTION METHOD FOR SILICON CARBIDE PARTS FOR NUCLEAR APPLICATIONS
}

\author{
Amy Elliott \\ Corson Cramer \\ Kurt Terrani
}

M3CT-19OR06090127

Date Published:

September 27, 2019

Prepared by

OAK RIDGE NATIONAL LABORATORY

Oak Ridge, TN 37831-6283

managed by

UT-BATTELLE, LLC

for the

US DEPARTMENT OF ENERGY

under contract DE-AC05-00OR22725 



\section{CONTENTS}

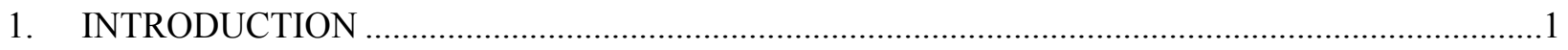

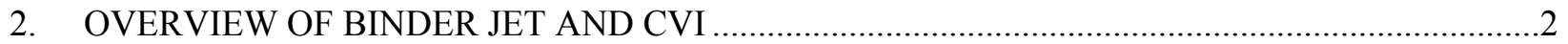

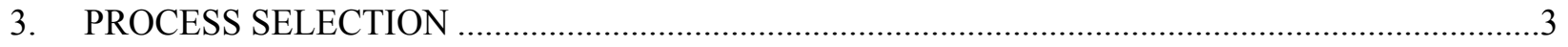

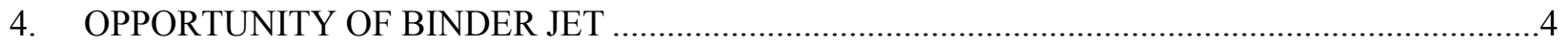

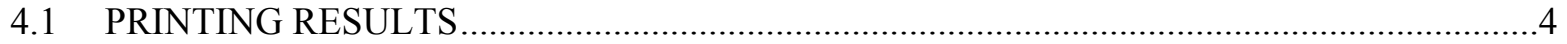

4.2 CHEMICAL VAPOR INFILTRATION OF SIC BINDER JET PARTS ................................5

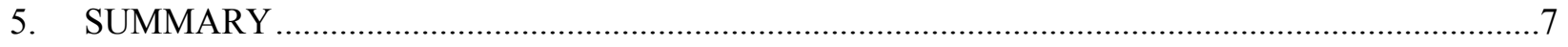

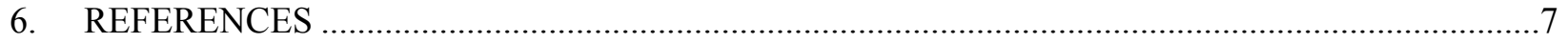




\section{INTRODUCTION}

Application of silicon carbide ( $\mathrm{SiC}$ ) is often sought within nuclear energy systems due to its high thermal conductivity, mechanical and environmental stability at elevated temperatures, corrosion resistance, and exceptional displacement damage irradiation tolerance [1-4]. As such, the transformational challenge reactor (TCR) program is considering its application in its additively manufactured core. SiC may be used as the matrix for the TCR fuel blocks that comprise of TRISO fuel particles embedded inside this material [5] or used as core non-fuel-bearing peripherical structures such as bottom support manifolds. The core peripherical structures serves to support the overall core geometry, direct and guide coolant flow, and also reflect back leaked neutrons into the core. SiC has very low neutron absorption and adequate scattering cross sections that makes it an ideal material for utilization in the TCR core.

Like many ceramics, however, $\mathrm{SiC}$ is difficult and at times impractical to shape into complex geometries via traditional machining due to its brittleness. Further, large structures comprising nuclear-grade $\mathrm{SiC}$, i.e. highly pure and crystalline, are costly. Additive manufacturing (AM), however, offers the ability to shape materials by adding layer-by-layer rather than subtracting, contributing new possibilities for previously difficult-to-shape materials. Thus, exploring AM as a method to shape $\mathrm{SiC}$ offers a highly cost-effective method and is strategic to developing the next generation of components for nuclear reactors. This report outlines an evaluation of binder jet additive manufacturing combined with chemical vapor infiltration (CVI) to produce nearly-dense silicon carbide artifacts in complex geometries suitable for advanced nuclear reactor designs. The focus is placed on the binder jet printing technologies at large scale for nonfuel-bearing structures relevant to the TCR core and other advanced reactors. Among all AM processes, binder jet delivers the highest resolution capability while still maintaining large print sizes, making it the ideal candidate for nuclear component production. 


\section{OVERVIEW OF BINDER JET AND CVI}

The process of creating SiC artifacts with binder jet and CVI involves shaping $\mathrm{SiC}$ powder on a binder jet system and then densifying the preform with CVI. Binder jet works by spreading powder into thin layers $(\sim 100 \mu \mathrm{m})$ and selectively depositing a binder into each layer with an inkjet printhead. After each layer is spread and the binder is deposited, the layer is lowered and the process continues with the next layer. Once the print is complete, the resulting bed or "build box" of powder is cured at $\sim 200^{\circ} \mathrm{C}$ overnight to drive the solvent out of the binder. At this point, the preforms are around $\sim 40 \%$ dense, are held together with the dried binder, and can be removed from the build box in a process known as depowdering. At this point, the preforms are ready for post-processing.

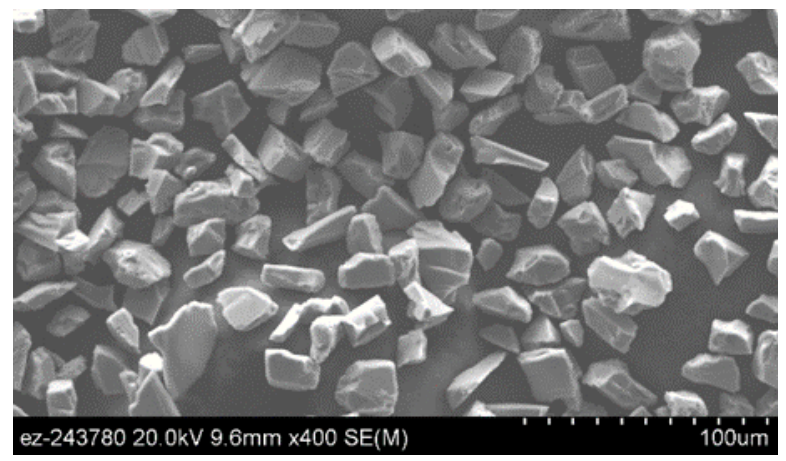

Figure 1. SiC feedstock imaged with SEM (feedstock from Sigma Aldrich).

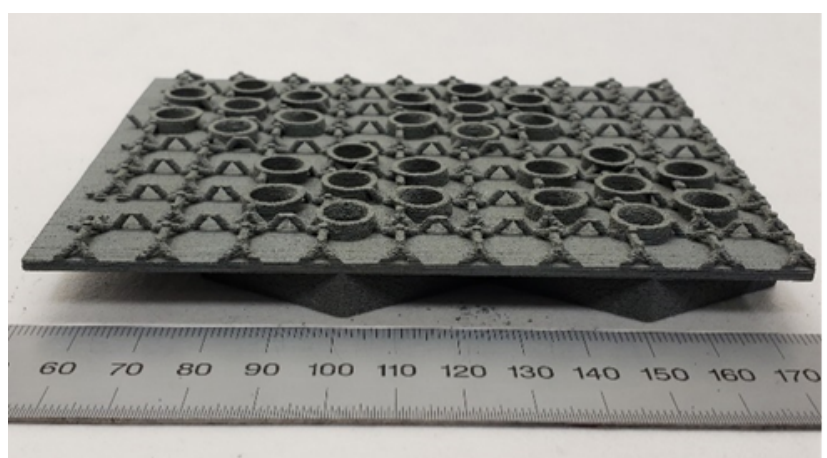

Figure 2. Image of binder jet $\mathrm{SiC}$ part (scale is in $\mathbf{m m})$.

The CVI process can be conducted on binder jet parts directly after depowdering and works by chemically converting gaseous precursors (e.g., ethyltrichlorosilane, ETS; or methyltrichlorosilane, MTS) into $\mathrm{SiC}$ on the surfaces of the porous preform. Once the preform is in the CVI chamber, the $\mathrm{SiC}$ deposition occurs between $800-1200^{\circ} \mathrm{C}$ [6] at sub-atmospheric pressures, Figure 3. As the CVI process progresses and as the $\mathrm{SiC}$ is deposited, the porosity in the part is slowly filled until the pores are closed. Typical density of the CVI-SiC artifacts derived from binder jet printing is $85-92 \%$ of theoretical density (with T.D. at $3.21 \mathrm{~g} / \mathrm{cm}^{3}$ ) by volume, which is highly suitable for the given application, offering adequate strength and thermal conductivity.

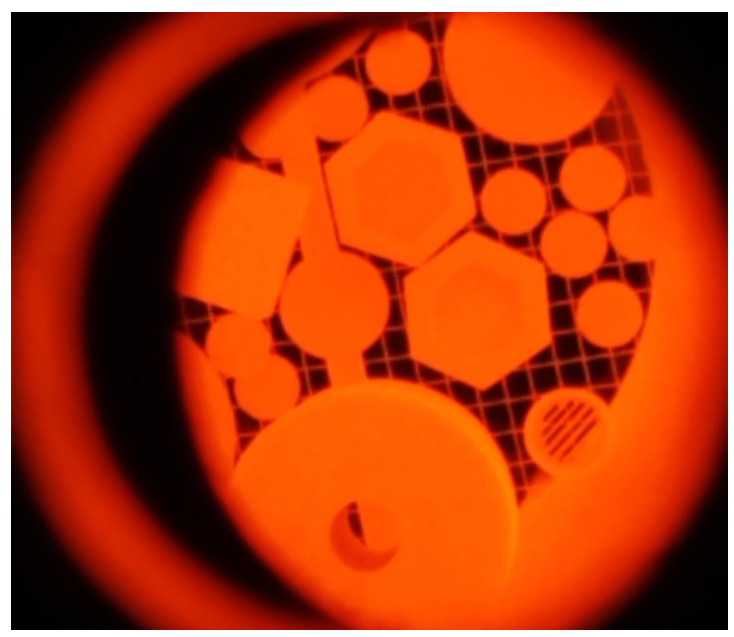

Figure 3. Inside view of the SiC CVI furnace with $\mathrm{H}_{2} / \mathrm{MTS}$ precursor mixture at $1000^{\circ} \mathrm{C}$ and 200 torr with binder jet printed SiC parts (courtesy of Brian Jolly, ORNL). 


\section{PROCESS SELECTION}

The down-selection to binder jet involved consideration of the seven different AM processes and the barriers to densifying powdered $\mathrm{SiC}$ via sintering or welding. Commonly used AM processes that were rejected because of these barriers include laser and electron beam powder bed fusion since the former cannot be used since $\mathrm{SiC}$ does not melt under atmospheric pressures and decomposes at temperatures above $2500^{\circ} \mathrm{C}$ [2]. Simultaneously, even if reaction forming (e.g., reacting mixtures of Si and C powders to form $\mathrm{SiC}$ via energy deposition in a system such as laser powder bed fusion) the necessary high temperatures would result in inevitable cracking from thermal gradients. Overall, the binder jet + CVI process [7] was chosen as the desired densification method for $\mathrm{SiC}$ powder for several reasons. First, relatively low-density $\mathrm{SiC}$ powder structures can be densified with CVI, meaning a variety of AM processes can be considered for the powder shaping step. Second, CVI can be conducted on parts of virtually any geometry, unlike common $\mathrm{SiC}$ densification techniques that require pressure from a geometrically-constrained die. Third, by utilizing high purity and highly crystalline powder during the binder jet process and following with CVI that if tuned correctly also deposits highly pure and crystalline $\mathrm{SiC}$, the final part offers a microstructure that is ideal for irradiation environment of nuclear energy systems. Finally, CVI can occur at relatively low temperatures, giving rise to the opportunity to embed objects into prints, such as sensors.

Given the selection of CVI as the densification method, indirect AM processes were considered, meaning AM processes that generate a powder preform that can be densified via CVI. These indirect methods include vat photopolymerization, material jetting, paste extrusion, and binder jet. The following list details the justification for the down selection to binder jet:

- Vat photopolymerization: High-density photopolymers form the matrix for the particles, which must be subsequently burned out. The residual matter from this burning operation will negatively affect the CVI process and the chemistry of the final SiC artifact (free carbon resulting in nonstoichiometry), which is unacceptable for nuclear applications.

- Material jetting: Printing ceramics with this technology is still in its infancy, and preliminary data on throughput for this process is extremely low.

- Paste extrusion: Resolution/accuracy and throughput are mutually exclusive. Further, geometric complexity is highly limited due to the lack of powder bed. Finally, the surface finish of extruded artifacts is constrained to a "corduroy" or stair-step texture, which may or may not be desirable for all surfaces. Also, similar to vat photopolymerization process, this method involves a lot of binder additives and will result in leftover undesirable residue in the material. 


\section{OPPORTUNITY OF BINDER JET}

Binder jetting has many advantages over other AM methods including production speed, being a room temperature and air environment process, scalability, geometric complexity, and material flexibility. First, binder jetting's high production speeds are due to the high deposition rates of the print head, which can occur within a few seconds for each layer despite how many parts are in the layer. Second, since binder jet printing occurs at room temperature and in a normal atmosphere, the machines are highly scalable in terms of size (e.g., no vacuum chamber or controlled atmosphere). Figure 4 is an image of a large sand cast mold part created on a binder jet machine in a single piece. Third, because binder jet is a powder bed process that inherently supports printed objects, complex geometries can be created much more readily than non-powder bed AM processes. Finally, because the binder system is able to bind virtually any material, binder jetting has high flexibility when it comes to material composition of the powder that is printed.

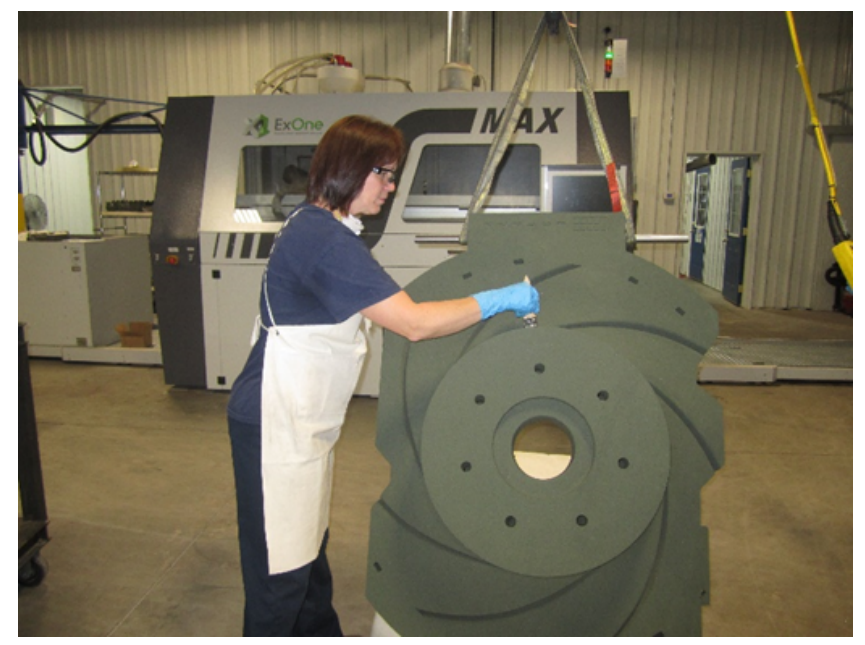

Figure 4. Sand cast mold printed on binder jet machine to demonstrate scalability of the process.

\subsection{PRINTING RESULTS}

Preliminary printing of large SiC preforms with ExOne's MFlex machine $(400 \times 250 \times 250 \mathrm{~mm}$ build envelope) had positive results as shown in Figure 5 and Figure 6. Multiple geometries were printed including hexagonal shells with complex internal geometry, mechanical test specimens, and a coolant flow manifolds, Figure 7. Each geometry was successfully depowdered with no noticeable defects. Similar preforms created on a smaller version of the MFlex (the Innovent) have been densified via CVI and characterized. 


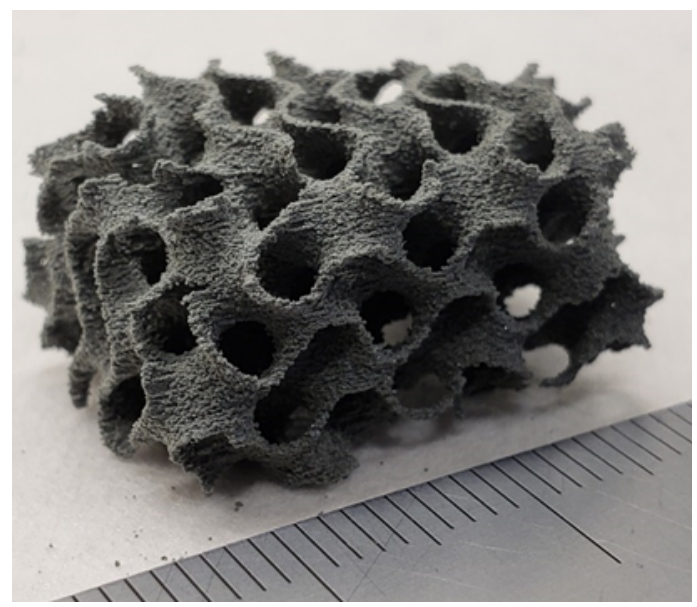

Figure 5. Complex geometry (gyroidal cube) printed on MFlex with SiC.

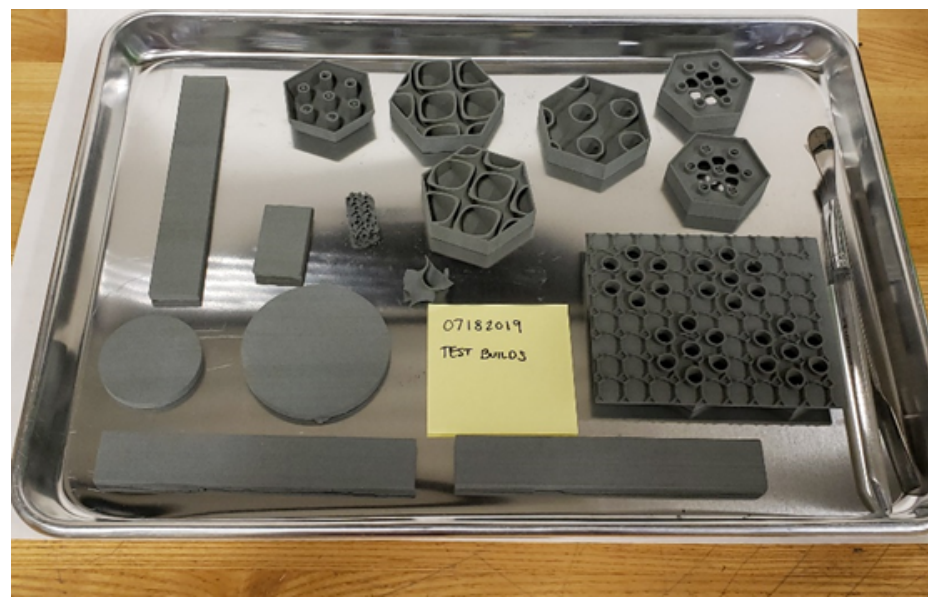

Figure 6. Single batch of parts created during a 4-hour print on the MFlex system.
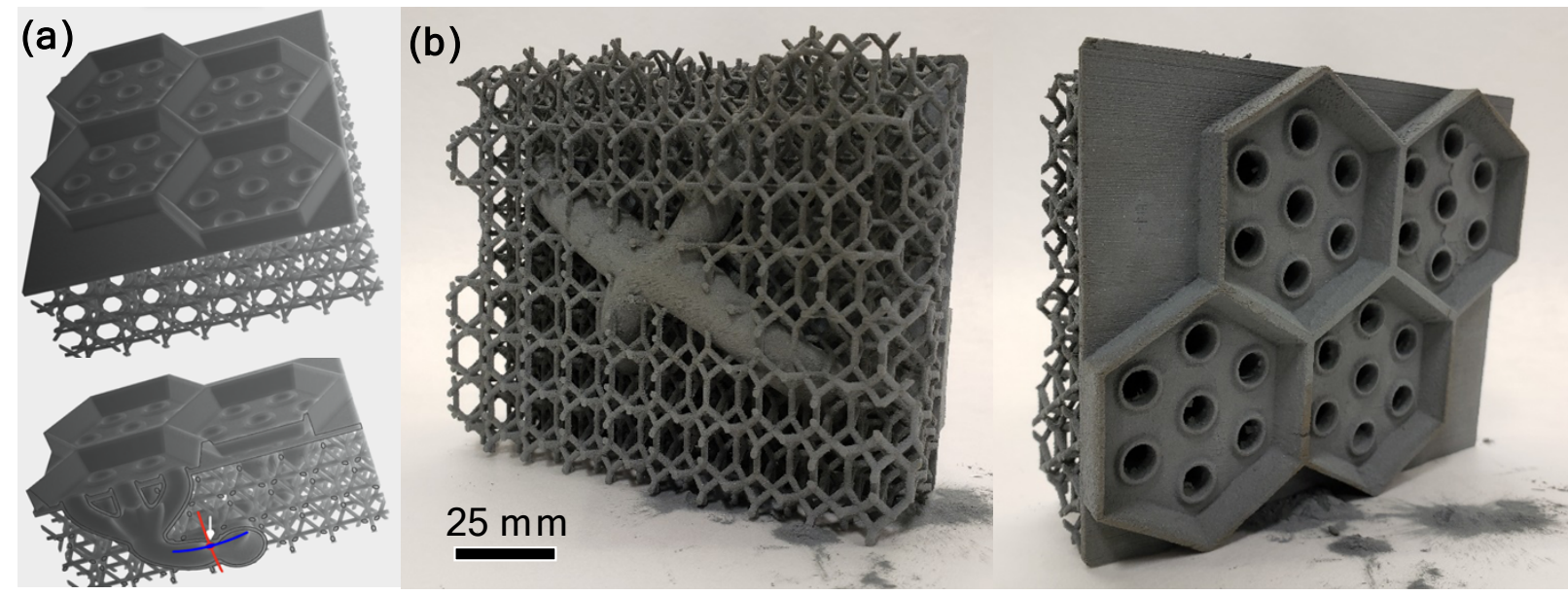

Figure 7. a) CAD design of SiC bottom manifold for TCR ceramic core concept showing the overall design as well as a cross section where coolant flow is directed. b) Actual builds of the part with large SiC binder jet system.

\subsection{CHEMICAL VAPOR INFILTRATION OF SIC BINDER JET PARTS}

It was shown that binder jetting can create complex preforms that can then successfully and repeatedly undergo CVI. Multiple parts have been infiltrated using a small CVI furnace (cylindrical build volume of $75 \mathrm{~mm}$ diameter and $125 \mathrm{~mm}$ height). The resulting parts were scanned via blue LED fringe projection method (Zeiss Comet system) to assess the final geometry of the part. The dimensional accuracy when comparing original CAD file to the final part from is within $\sim 1 \%$, Figure 8 . The final thermal and mechanical properties of the infiltrated and densified $\mathrm{SiC}$ parts has been measured and is reported in [8]. 

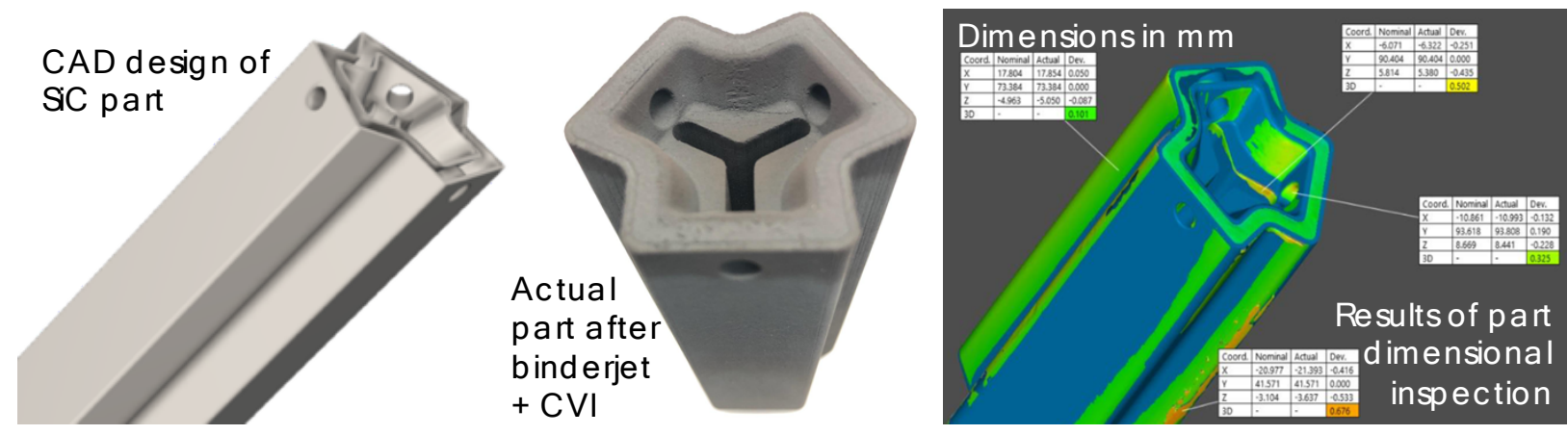

Figure 8. Workflow showing CAD file, resulting advanced manufactured SiC components, and results from dimensional inspection of the actual part. Dimensional inspection compares geometrical values in cartesian coordinates from the original CAD file and those there were measured on the part and also reports the difference between the two (Courtesy of Brian Jolly and Andres Marquez Rossy).

In order to infiltrate the larger non-fuel-bearing components such as those shown in Figure 7, larger CVI furnaces are necessary. Fortunately, CVI is a highly scalable technology with large industrial furnaces available. Figure 9 shows an example of a commercial furnace with 20 -liter build volume. The same manufacturer offers larger systems up to 11,000 liters in build volume. The TCR program is currently in the process of acquiring two systems with 20 - and 100-liter build volumes to facilitate infiltration of large $\mathrm{SiC}$ components.

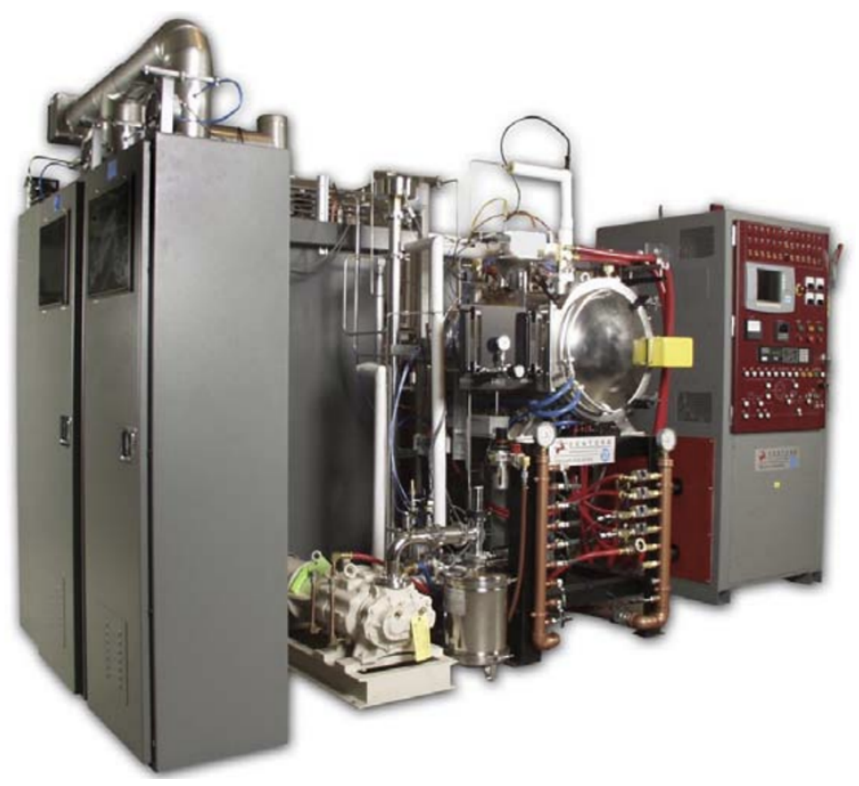

Figure 9. Series 3800 Model 8820-1600 SiC CVD reactor (20-liter build volume) from Centorr Vacuum Industries (Nashua, NH). 


\section{SUMMARY}

Silicon carbide offers exceptional properties for nuclear energy applications and therefore, it is considered as a constituent of TCR core. SiC is difficult and expensive to form and machine, so its additive manufacturing is highly desirable. This report provides an overview of potential technologies for this purpose and explains the logic for down-selection of a unique approach for additive manufacturing of $\mathrm{SiC}$. This approach leverages a unique combination of binder jet printing and chemical vapor infiltration technologies to showcase viability for production of nuclear-grade $\mathrm{SiC}$ ceramics at relatively large scales. This approach is ideal to realize non-fuel-bearing structures peripherical to the TCR core.

\section{REFERENCES}

[1] S.J. Zinkle, K.A. Terrani, L.L. Snead, Motivation for utilizing new high-performance advanced materials in nuclear energy systems, Curr. Opin. Solid State Mater. Sci. 20 (2016) 401-410.

[2] L.L. Snead, T. Nozawa, Y. Katoh, T.S. Byun, S. Kondo, D.A. Petti, Handbook of SiC properties for fuel performance modeling, J. Nucl. Mater. 371 (2007) 329-377. doi:10.1016/j.jnucmat.2007.05.016.

[3] K.A. Terrani, B.A. Pint, C.M. Parish, C.M. Silva, L.L. Snead, Y. Katoh, Silicon carbide oxidation in steam up to $2 \mathrm{MPa}$, J. Am. Ceram. Soc. 97 (2014). doi:10.1111/jace.13094.

[4] Y. Katoh, T. Nozawa, L.L. Snead, K. Ozawa, H. Tanigawa, Stability of SiC and its composites at high neutron fluence, J. Nucl. Mater. 417 (2011) 400-405. doi:10.1016/j.jnucmat.2010.12.088.

[5] M.P. Trammell, B.C. Jolly, M.D. Richardson, A.T. Schumacher, K.A. Terrani, Advanced Nuclear Fuel Fabrication: Particle Fuel Concept for TCR, ORNL/SPR-2019/1216, M3CT-19OR06090130, 2019.

[6] Y. Katoh, K. Ozawa, C. Shih, T. Nozawa, R.J. Shinavski, A. Hasegawa, L.L. Snead, Continuous $\mathrm{SiC}$ fiber, CVI SiC matrix composites for nuclear applications: Properties and irradiation effects, J. Nucl. Mater. 448 (2014) 448-476. doi:10.1016/j.jnucmat.2013.06.040.

[7] K. Terrani, B. Jolly, M. Trammell, 3D printing of high-purity silicon carbide, J. Am. Ceram. Soc. submitetd (2019).

[8] K.G. Field, J. Simpson, M.N. Gussev, H. Wang, M. Li, X. Zhang, X. Chen, T. Koyanagi, K. Kane, A.M. Rossy, M. Balooch, K.A. Terrani, Handbook Of Advanced Manufactured Material Properties From TCR Structure Builds at ORNL_ FY 2019, ORNL/TM-2019/1328, M3CT19OR06090121, 2019. 